\title{
RANCANG BANGUN APLIKASI MOBILE E-KOST MENGGUNAKAN LOCATION BASED SERVICE (LBS) BERBASIS ANDROID
}

\author{
Martza Merry Swastikasari ${ }^{1}$, Renee Yosua Hetharie ${ }^{2}$, Eko Sediyono $^{3}$, Anwar S. Ardjo ${ }^{4}$ \\ ${ }_{1,2,3,4}$ Magister Sistem Informasi, Fakultas Teknologi Informasi, \\ Universitas Kristen Satya Wacana \\ Email: ${ }^{1}$ martza.swastikasari@gmail.com, ${ }^{2}$ reneeyosua@yahoo.com, ${ }^{3}$ ekosed1@yahoo.com, \\ ${ }^{4}$ anwars.ardjo@gmail.com
}

\begin{abstract}
Abstrak
Perkembangan perangkat mobile, teknologi-teknologi yang canggih serta gaya hidup yang semakin modern, membuat setiap manusia ingin terus berinovasi dalam menggunakan sebuah aplikasi yang bertujuan untuk mempermudah serta mengefisiensi waktu yang ada, diantaranya adalah membuat atau menggunakan sebuah sistem yang dapat membuat segala sesuatu menjadi serba instant dan cepat. Sejalan dengan fakta tersebut, penulis bertujuan membuat sebuah aplikasi mobile pencarian rumah kost berbasis android dengan mengunakan teknologi Located Based Service (LBS), sehingga memudahkan mahasiswa khususnya dalam mencari kost yang di butuhkan, serta tak lupa untuk pemilik/pengelola kost dalam mempromosikan serta menawarkan usahanya kepada orang lain. Metode yang digunakan adalah metodologi Object Oriented Business Application Development dan menjadikan Codeigniter sebagai framework sistem. Hasil akhir dari penelitian ini adalah sebuah prototype aplikasi mobile berbasis android, sehingga dalam penelitian selanjutnya dapat digunakan sebagai acuan dalam pembuatan dan pengembangan lebih lanjut, sehingga dapat di aplikasikan dan digunakan sesuai kebutuhan user.
\end{abstract}

Kata kunci : Location Based Service (LBS), E-KOST, Android

\begin{abstract}
The development of mobile devices, technologies advanced and modern lifestyles, make every human being wants to continue to innovate in using an application that aims to simplify and efficiency time available, such as creating or using a system that can make everything completely instant and fast. In line with this fact, the author aims to create a mobile application based on Android boarding house searches by using technology Located Based Service (LBS), making it easier for students especially in finding a boarding house, and do not forget to owners I managers of boarding in promoting and offering his business to someone else. The method used is the methodology of Object Oriented Business Application Development and make CodeIgniter as the framework of the system. The end result of this research is a prototype android based mobile application, so that in future studies can be used as a reference in the manufacture and further development, so it can be applied and used in accordance with user needs
\end{abstract}

Keywords : Location Based Service (LBS), E-KOST, Android 


\section{PENDAHULUAN}

Perkembangan perangkat mobile khususnya smartphone dan tablet akhir-akhir ini sudah bisa dikatakan sangat pesat. Mulai dari jumlah pengguna yang semakin lama semakin meningkat sampai berbagai macam ketersediaan perangkat mobile pun meningkat secara drastis. Teknologi mobile juga sudah semakin berkembang dengan disediakannya berbagai platform seperti Android, Blackberry, iOS dan Windows Mobile. Menurut website IDC.com (International Data Corporation) yang merupakan sebuah website yang menangani survey tentang data pengguna perangkat mobile khususnya smartphone dan tablet di dunia menunjukkan hasil survey 2015 bahwa smartphone yang berbasis Android memiliki pangsa pasar tertinggi di dunia dengan persentasi 82,3\%, diikuti oleh $\operatorname{IOS} 13,8 \%$, dan Windows Mobile $2,7 \%$. Berdasarkan data diatas, membuktikan bahwa teknologi mobile pada saat ini sudah memasuki masa yang sangat berkembang jika di bandingkan dengan satu dekade yang lalu [1].

Sejalan dengan perkembangan tersebut, keberadaan mobile device (smartphone) sudah semakin menyatu dengan kehidupan personal manusia. Salah satu bentuk perkembangan tersebut adalah kemudahan seseorang untuk memperoleh informasi tentang lokasi suatu tempat. Mereka dapat mengakses informasi yang mereka butuhkan dimana saja dan kapan saja bahkan mobile device yang mereka miliki dapat mengetahui lokasi keberadaan mereka secara langsung maupun tidak langsung. Salah satu teknologi mobile yang sangat membantu bagi seseorang untuk mengetahui keberadaannya serta mengetahui lokasi tempat yang akan di datanginya adalah Location Based Service (LBS) [1].

Berdasarkan teknologi LBS ini, muncullah sebuah ide untuk mencoba menerapkannya dalam sebuah aplikasi mobile yang dinamakan E-KOST, yang berjalan pada platform Android. E-KOST ini merupakan sebuah aplikasi pencarian kost-kostan bagi mahasiswa UKSW. UKSW terkenal dengan sebutan "Indonesia Mini", dimana mahasiswanya sebagian besar datang dari berbagai penjuru kota di Indonesia. Berdasarkan fakta tersebut serta kurangnya pemahaman mengenai letak kost di kota Salatiga, mahasiswa baru akan susah untuk mencari / menentukan kost mana yang akan di jadikan tempat tinggal. Hal tersebut tidak terbatas pada mahasiswa baru saja, tetapi juga pada mahasiswa lama yang sudah tidak merasa nyaman dengan kost yang ditingggali saat ini. E-KOST ini bisa dijadikan alat yang menguntungkan untuk mencari kostkostan di kota Salatiga (dengan jarak tertentu), baik di saat mereka masih di kota asal ataupun sudah berada di Salatiga. Aplikasi E-KOST ini akan menampilkan fitur-fitur yang user-friendly atau nyaman di gunakan sehingga dapat digunakan oleh siapa saja. Selain menjadi tool pencarian yang handal bagi mahasiswa, aplikasi ini juga dapat digunakan oleh pemilik kost sebagai media promosi untuk mempromosikan kost yang dikelola, mulai dari penyajian fasilitas, lingkungan, ukuran kamar, bahkan harga yang bersaing.

\section{KAJIAN PUSTAKA}

\subsection{Penelitian Sebelumnya}

\subsubsection{Sistem Informasi Geografis Pemetaan Tempat Kost Berbasis Web}

Pada penelitian ini, penulis yang berlokasi di area Pontianak mencoba merancang sebuah sistem informasi tempat kost yang didasarkan pada letak geografisnya. Sistem yang dibangun lebih ditujukan pada penggunaan peta online atau google maps sebagai fasilitas dalam pencarian tempat kost dengan kategori yang cukup sempit seperti perhitungan jarak (rumah) kost, biaya sewa, fasilitas umum, ukuran kamar, jumlah penghuni, dan lain - lain. Sistem perangkat lunaknya juga dikembangkan dengan metode Linear Sequential / Waterfall Model. Sistem yang telah di buat, masih terdapat beberapa kelemahan dan perbaikan, seperti koordinat lokasi (rumah) kost harus benar - benar valid karena hal ini terkait dengan letak lokasi rumah pada google maps, perlu adanya sosialisasi kepada pemilik kost agar dapat lebih dapa berpartisipasi 
aktif dalam mempromosikan kepada masyarakat luas dengan menggunakan website, dan yang terakhir penulis menyarankan agar sistem dikembangkan lebih lanjut dengan menggunakan perangkat mobile, agar GIS pemetaan lokasi dapat diakses dengan mudah [2]. Perbedaan penelitian yang dilakukan oleh kami adalah dari segi penggunaan dan fitur yang disediakan. Aplikasi yang dibuat harus sebisa mungkin user-friendly kepada semua user, entah mahasiswa atau pengelola kost, sehingga pilihan menggunakan basis android menjadi pilihan utama dalam pengaplikasiannya, mengingat smartphone android bukan lagi menjadi hal yang baru. Metode yang digunakan juga menggunakan object oriented, sehingga memaksimalkan kebutuhan aplikasi yang akan dibangun.

\subsubsection{Sistem Informasi Tempat Kost Di Sekitar Universitas Muhammadiyah Surakarta}

Pada penelitian ini, penulis mencoba membangun sebuah sistem informasi kost yang berbasis web. Tujuannya adalah mempermudah mahasiswa dalam mencari tempat kost dan memberi informasi detail tentang gambaran kost tersebut. Selain itu, sistem ini juga membantu pemilik kost dalam mempromosikan kostnya secara online. Sistem yang dibangun menggunakan metode penelitian SDLC (System Development Life Cycle), yaitu sebuah siklus hidup pengembangan sistem, dan beberapa software pendukung, diantaranya appserv untuk menjalan web servernya, MySQL untuk mengelola database, Adobe Dreamweaver CS5 sebagai tool untuk membuat script dalam bahasa HTML, PHP dan Javascript. Dari hasil yang telah ada, ternyata sistem ini masih sulit untuk digunakan oleh masyarakat awam, karena memiliki struktur data yang sulit. Selain itu karena sistem ini berbasis web, kemungkinan masih ada beberapa pemilik kost yang tidak dapat mengakses dengan baik karena kendala sinyal dan internet [3]. Perbedaan penelitian yang dilakukan oleh kami adalah dari segi penggunaan dan fitur yang disediakan. Aplikasi yang dibangun user-friendly, sehingga terhindar dari struktur data yang rumit sehingga mudah diakses oleh siapa saja. Metode yang digunakan juga menggunakan object oriented, sehingga memaksimalkan kebutuhan aplikasi yang akan dibangun, dan menggunakan framework CodeIgniter, dimana admin dapat melakukan update sistem dengan mudah agar menjadi lebih baik.

\subsubsection{Perancangan Aplikasi Mobile Pencarian Lokasi Penyewaan Rumah Kost Berbasis Android di Kota Jogyakarta}

Pada penelitian ini, penulis mencoba merancang sebuah sistem aplikasi pencarian kost berbasis android yang memiliki tujuan membantu para pelajar untuk mencari lokasi kost-kostan yang terdekat dan sesuai kebutuhan dari pelajar tersebut. Sistem Aplikasi yang dibangun menggunakan Google Maps sebagai pemetaan lokasi kost dan XAMPP yang dipakai sebagai server, yang terdiri atas basis data MySQL yang berfungsi sebagai media penyimpanan data. Untuk dapat mengakses informasi yang ada pada basis data melalui mobile Android maka dibuat sebuah pertukaran data yang dipanggil melalui JQueryMobile menggunkan Eclipse IDE. Dari hasil yang telah ada, ternyata sistem ini masih memiliki banyak keterbatasan, karena memiliki struktur data yang sulit. Selain itu aplikasi yang dibuat juga belum terintegrasi dengan JQueryMobile jadi aplikasi belum bisa menyesuaikan ukuran layar pada ponsel kita dan Aplikasi ini hanya berjalan pada smartphone android dengan menggunakan minimal Android OS [4]. Perbedaan penelitian yang dilakukan oleh kami adalah aplikasi kami dilengkapi dengan halaman user bisnis atau pengelola kost. Pada halaman ini, pengelola kost dapat dengan jelas menginput semua yang dianggap penting (seperti gambar dan keterangan) dalam mempromosikan kost mereka, juga dilengkapi dengan sistem booking yang otomatis tanpa campur tangan dari admin. 


\subsection{Karakteristik User}

Dalam membangun sistem ini, ada beberapa user yang terlibat dalam sistem pengoperasiannya, user yang dimaksud adalah :

- $\quad$ Admin

Admin disini memiliki banyak fungsi, diantaranya untuk merancang, membuat, mengupgrade serta mengelola data dan sistem yang ada. Admin juga memiliki hak untuk membatasi kegiatan user pada sistem apabila dinilai tidak bertanggung jawab atas hal-hal yang dilakukan.

- $\quad$ User Individu

User Individu adalah mahasiswa, user individu memiliki hak akses untuk melakukan permintaan pemesanan kamar, serta melakukan filter pencarian berdasarkan dengan kebutuhan yang diinginkan. User individu juga dapat melakukan kontak langsung dengan pengelola kost, apabila merasa kurang yakin dengan data yang ditampilkan.

- User Bisnis

User bisnis disini adalah pengelola kost. Mereka akan mendapat sebuah halaman yang dinamis dalam mengelola katalog-katalog data yang dimiliki dalam bentuk tulisan dan gambar, serta mengetahui siapa saja yang telah berkunjung ke halaman mereka. User bisnis juga dapat mengetahui siapa saja yang melakukan pemesanan kamar serta dapat melakukan block user bagi siapa saja yang dianggap kurang serius.

\section{METODE PENELITIAN}

Metode yang digunakan dalam membangun sistem aplikasi mobile E-KOST berbasis Android adalah metode Object Oriented Business Application Development.

\subsection{Requirement Engineering}

Requirement engineering merupakan fase awal dalam pembangunan rekayasa perangkat lunak. Hal ini terdiri atas 3 tahap, yaitu Elicitation, Spesification, dan Validation and Verification.

\section{a. Elicitation}

Elication merupakan proses pengumpulan data requirement (kebutuhan) dari user dan teknik pengumpulan data atau metodologi biasanya menggunakan proses interviewing, brainstorming, prototype, use case diagram, dll.

Teknik Wawancara dan Kuisioner

Teknik wawancara dan kuisioner yang dilakukan guna mendapatkan apa saja yang dibutuhkan oleh pengguna dari sistem yang dirancang. Sistem wawancara dan kuisioner dilakukan pada 2 pihak users, yaitu mahasiswa dan pemilik rumah kost.

Pertanyaan untuk user individu (mahasiswa) :

1. Apa yang menjadi prioritas utama dalam mencari sebuah kamar kost?

2. Fasilitas apa saja yang seharusnya tersedia dalam sebuah rumah kost?

3. Bagaimana cara terbaik dalam mencari kost yang sesuai dengan kebutuhan?

4. Apa kelemahan dari cara tradisional yang selama ini digunakan dalam mencari kost?

5. Lokasi / tempat apa saja yang dianggap strategis yang harus berdekatan dengan rumah kost? 
6. Apa dampak yang ditimbulkan apabila kost yang di tinggali tidak sesuai dengan keinginan?

7. Seberapa pentingkah peran ibu kost dalam sebuah rumah kost yang menjadi satu dengan pemiliknya?

8. Apakah harga yang murah menjadi satu - satunya alasan seorang anak kost memilih sebuah rumah kost?

9. Fasilitas exclusive seperti kolam renang dan rumah bertingkat, apakah menjadi salah satu syarat utama yang harus di penuhi dalam sebuah rumah kost?

Pertanyaan untuk user bisnis (pengelola/pemilik kost):

1. Apa yang menjadi indikator utama dalam menerima anak kost?

2. Kiat - kiat apa saja yang dilakukan dalam mempromosikan/mengiklankan kost yang di kelola?

3. Kendala - kendala yang dihadapi saat menerima anak kost yang tidak sesuai dengan prediksi?

4. Apa yang menjadi kebutuhan utama seorang anak kost?

5. Apa saja kelemahan cara tradisional yang dilakukan dalam melakukan promosi kostkostan?

Berdasarkan hasil wawancara dan kuisioner yang dibagikan, maka dapat disimpulkan kebutuhan-kebutuhan secara fungsional dan non fungsional adalah:

1. Sistem dapat menampilkan berbagai macam pilihan kost yang berlokasi strategis dengan harga murah.

2. Sistem dapat menampilkan fasilitas-fasilitas penunjang yang dimiliki oleh setiap kost, seperti dapur, tempat parkir, internet, dan lain-lain.

3. Sistem selalu dapat mengupdate pilihan-pilihan kost terbaru setiap jangka waktu tertentu.

4. Sistem dapat di download dan tersimpan dalam smartphone, sehingga kapanpun dan dimanapun, aplikasi dapat di akses. Hal ini terasa lebih efektif dan efisien dibandingkan dengan cara tradisional yang selama ini digunakan masing-masing user.

5. Bisa melakukan booking atau pemesanan kamar via online sehingga kamar yang diinginkan tidak diambil orang.

6. Sistem dapat melakukan handling error sehingga pengaksesan aplikasi tidak terhambat.

7. Sistem dapat menampilkan related post mengenai beberapa rumah kost, yaitu kost yang memiliki rating tertinggi dengan review terbaik.

8. Sistem dapat dijadikan alat untuk promosi yang handal.

9. Sistem dapat menampilkan radius atau jarak serta petunjuk jalan ke setiap rumah kost yang terdaftar.

10. Sistem tidak berbayar (free).

11. Sistem yang user friendly (mudah dalam penggunaan), baik untuk mahasiswa bahkan orang awam sekalipun.

12. Sistem bisa diakses dari luar pulau atau luar kota, sehingga memudahkan calon bahkan mahasiswa bisa memilih kost yang akan dituju.

13. Jika dimungkinkan, sistem bisa menampilkan pula lokasi-lokasi strategis lainnya seperti warung makan terdekat, shopping mart terdekat, penyewaan mobil dan motor terdekat, tempat foto copyan terdekat, dan lain-lain.

14. Sistem tidak bersifat monotone, dari segi interface dan desain halaman, sehingga tidak terlihat membosankan bagi yang mengunjunginya.

15. Sistem di harapkan bisa menampilkan fitur-fitur aplikasi yang memudahkan pengelola menampilkan keselurahan info mengenai kost yang di kelola yaitu dengan menampilkan satu halaman dinamis untuk masing-masing user yang telah melakukan registrasi. 
16. Sistem harus benar-benar terintegrasi dengan data real yang ada, dan terjalin kepercayaan antar semua pihak, sehingga users yakin akan data yang ditampilkan.

17. Sistem mampu menjadi solusi terbaik users khususnya yang memiliki kendala dengan cara sebelumnya.

\section{b. Specification}

Specification adalah proses selanjutnya dari elicitation. Proses ini berisi tentang fitur dan fungsi yang diinginkan oleh users, serta sama sekali tidak membahas bagaimana metode pengembangannya. Dari proses elicitation yang dilakukan, berikut definisi masalah umum yang sudah ada :

- Mahasiswa memiliki kendala yang cukup sulit dalam mendapatkan informasi detail kamar kost yang dibutuhkan sehingga mempersulit proses pencarian. Hal yang dapat dilakukan adalah mencari tahu informasi kost - kostan dari orang lain atau mengecek satu persatu kamar kost yang sekiranya dilewati.

- Bagi mahasiswa yang berasal dari luar kota / luar pulau akan semakin sulit dalam mencari kost yang diinginkan, selain belum mengetahui lokasi menyeluruh mengenai kota Salatiga dan kampus UKSW, mereka juga memiliki minim informasi mengenai kost kostan yang ada.

- Si pengelola kost merasa kurang efektif dalam mengiklankan kost yang dikelola, karena terbatas pada area dan jangkauan. Mereka melakukan pengiklanan dengan cara seadanya karena tidak mengetahui cara apa yang efektif dalam mempromosikan kost nya.

Karakteristik sistem yang dibangun bagi pengguna:

- Menyediakan sarana informasi secara praktis dan cepat mengenai letak dan detail dari kost-kostan yang tersedia. Aplikasi dapat diakses di mana saja dan kapan saja sehingga mempermudah calon mahasiswa untuk menentukan pilihan, melakukan pemesanan dan pembayaran.

- Kamar kost yang tersedia pada sistem aplikasi dapat dijadikan referensi bahan pertimbangan dalam memilih kost-kostan yang akan ditempati (baik pertimbangan dari segi fasilitas, jarak maupun harga yang ditawarkan). Dengan menggunakan fitur google maps, penyewa juga dapat memilih kost yang strategis dengan melihat langsung lokasi kost yang diinginkan, sehingga sangat memudahkan mahasiswa dari luar kota yang hendak melakukan studi ke UKSW.

- Sistem yang dibangun akan menerima pembayaran booking kamar, sehingga mahasiswa tidak perlu lagi jauh-jauh datang dari luar kota hanya untuk melakukan booking kamar. Pembayaran ini nantinya akan langsung cair kepada pemilik kost apabila si penyewa melakukan check in pada sistem, sehingga di wajibkan setiap mahasiswa yang akan melakukan pencarian memiliki satu akun yang berisikan beberapa atribut penting yang nantinya akan di gunakan untuk keperluan pemesanan kamar dan untuk login sistem.

- Sistem kemungkinan akan dijadikan ajang persaingan bagi setiap pemilik kost, karena mereka akan berusaha memperbaiki kekurangan kost yang dimiliki. Dengan sistem ini, setiap pemilik kost dapat mengakses detail halaman kost lainnya sehingga mereka mengetahui fasilitas-fasilitas apa saja yang dimiliki oleh kost lainnya.

Cakupan dalam pembuatan sistem

Detail data kost dapat dikembangkan dan dijadikan acuan untuk menentukan pilihan kost yang sesuai kebutuhan.

Fitur - fitur dalam pembuatan sistem

- Membuat kategori pencarian yang akan dimasukan kedalam Google Maps, sehingga users dapat melakukan pencarian hanya dengan mengetikkan nama kost atau alamat yang dituju. 
- Menyiapkan desain interface yang menarik serta prosedur penggunaam aplikasi yang mudah (user friendly) sehingga orang awan sekalipun tidak mengalami kesulitan dalam pengoperasiannya.

- Membuat sistem pembayaran yang mudah, sehingga mahasiswa yang akan melakukan booking kamar tidak mengalami kesulitan dalam melakukan pembayaran dan penginputan bukti pembayaran.

- Sistem akan menampilkan beberapa kategori pencarian, seperti radius kejauhan, rating kost, harga, dan fasilitas.

- Sistem akan menyiapkan fitur chatting, fungsinya adalah mahasiswa dapat melakukan kontak langsung dengan pemilik kost yang terdaftar via SMS, Whatsapp, dan Email. Dengan adanya fitur ini, pemiliki kost mampu memaparkan secara jelas apa yang sudah tertera pada halaman kost miliknya kepada mahasiswa, sehingga mahasiswa sendiri mengerti mengenai halaman kost yang sedang dikunjunginya.

\section{c. Validation and Verification}

Bagian ini berisi tentang data yang akan di validasi setelah dilakukannya beberapa proses sebelumnya. Bagian ini memastikan pula bahwa sistem telah memahami masalah yang akan di pecahkan. Berikut uraiannya:

- Pernyataan 1 :

Mahasiswa memiliki kendala yang cukup sulit dalam mendapatkan informasi detail kamar kost yang dibutuhkan sehingga mempersulit proses pencarian. Hal yang dapat dilakukan adalah mencari tahu informasi kost-kostan dari orang lain atau mengecek satu persatu kamar kost yang sekiranya dilewati.

\section{Aksi :}

Sistem dengan basis android ini akan menampilkan secara jelas kost yang di cari berdasarkan kategori pencarian yang diinginkan, mulai dari radius jarak, fasilitas, dan harga.

Semua dapat dilakukan pada handphone anda di mana saja dan kapan saja selama persediaan kamar kosong masih ada.

\section{- Pernyataan 2:}

Bagi mahasiswa yang berasal dari luar kota / luar pulau akan semakin sulit dalam mencari kost yang diinginkan, selain belum mengetahui lokasi menyeluruh mengenai kota Salatiga dan kampus UKSW, mereka juga memiliki minim informasi mengenai kost-kostan yang ada.

\section{$\underline{\text { Aksi : }}$}

Sistem ini akan dilengkapi dengan fitur google maps, dimana mahasiswa dapat melihat lokasi yang diinginkan hanya dengan mengetikan nama kost atau alamat yang di tuju. Sistem juga akan menampilkan radius jarak kost dengan kampus sehingga mahasiswa mengetahui lokasi kost yang strategis. Selain dilengkapi dengan fitur penunjuk arah google maps, sistem juga akan dilengkapi dengan beberapa kategori pemilihan kost.

- Pernyataan 3 :

Pengelola kost merasa kurang efektif dalam mengiklankan kost yang dikelola, karena terbatas pada area dan jangkauan. Mereka melakukan pengiklanan dengan cara seadanya karena tidak mengetahui cara apa yang efektif dalam mempromosikan kost nya.

Aksi : 
Sistem akan menyediakan halaman dinamis untuk user bisnis sehingga diwajibkan bagi setiap user bisnis memiliki akun pribadi untuk dapat melakukan login, halaman ini memudahkan si pengelola kost dalam mengelola data yang ada, mulai dari menambah, menghapus bahkan mengedit data. Disediakan pula fasilitas chatting yang dimana memudahkan berkomunikasi langsung dengan calon penyewa.

\subsection{Perancangan Berorientasi Objek}

\subsubsection{Use Case Diagram}

Use case diagram menyajikan interaksi antara use case dan actor. Dimana, aktor dapat berupa orang, peralatan, atau sistem lain yang berinteraksi dengan sistem yang sedang dibangun. Use case menggambarkan fungsionalitas sistem atau persyaratan-persyaratan yang harus dipenuhi sistem dari pandangan pengguna[5].

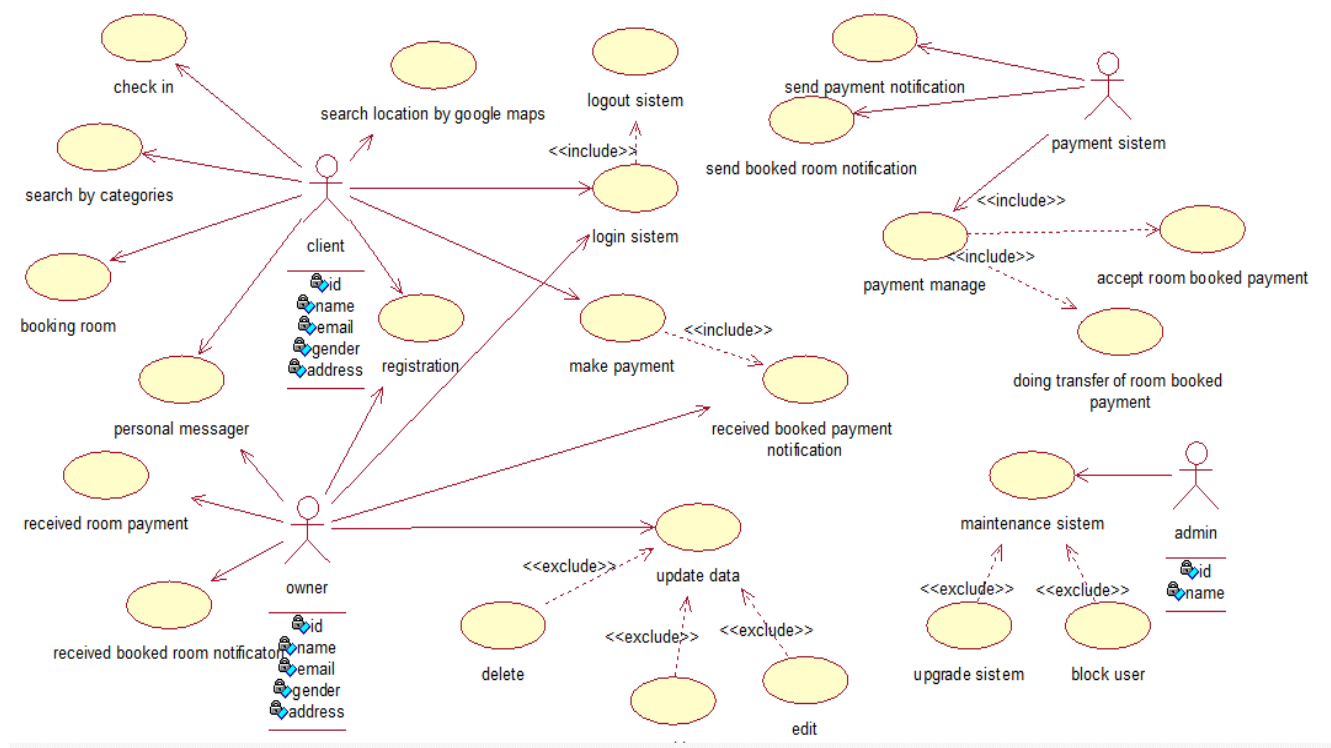

Gambar 1. Use Case Diagram Aplikasi E-KOST

\subsubsection{Class Diagram}

Class Diagram merupakan inti dari pengembangan dan desain berorientasi objek. Class menggambarkan keadaan (atribut/properti) suatu sistem, sekaligus menawarkan layanan untuk memanipulasi keadaan tersebut (metoda/fungsi). Class diagram menggambarkan struktur dan deskripsi class, package, dan obiek vang berhubungan satu sama lain seperti containment, asosiasi, dan lain -

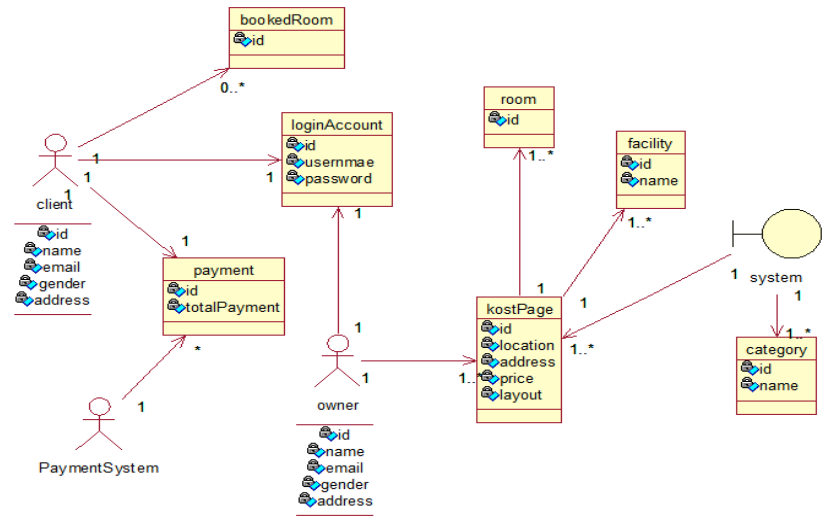

Gambar 2. Class Diagram Aplikasi E-KOST 


\subsection{Perancangan Prototype}

Berdasarkan diagram yang telah dibuat, langkah selanjutnya adalah melakukan desain interface (Prototype) mengenai aplikasi yang akan dibuat. Desain interface ini selanjutnya akan dijadikan acuan dalam pembuat aplikasi yang sebenarnya. Berikut beberapa desain tampilan utama aplikasi yang dibuka melalui smartphone Android.

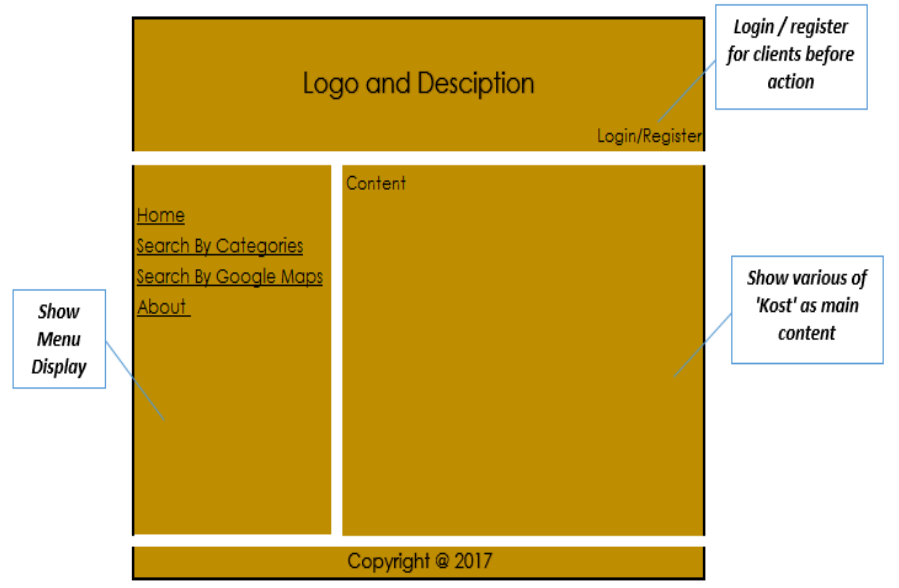

Gambar 3. Desain Interface Layout Utama

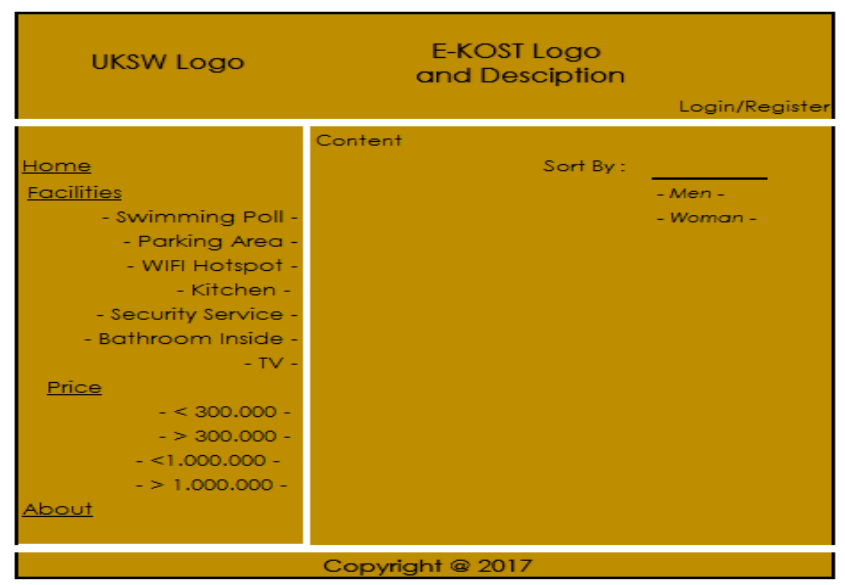

Gambar 4. Desain Interface Search By Categories

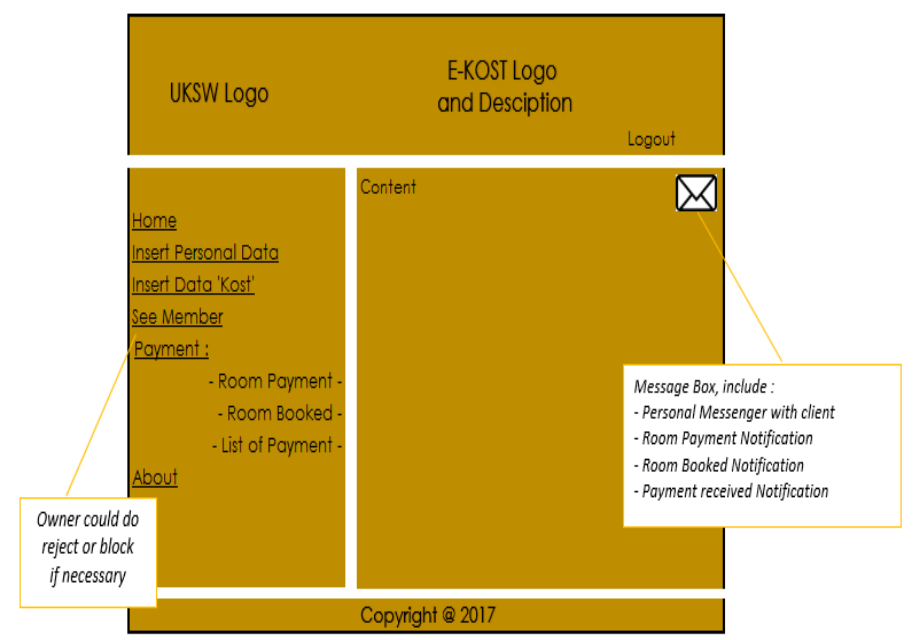

Gambar 5. Desain Interface Halaman Utama Owner/Pengelola Kost (User Bisnis) 
Computatio: Journal of Computer Science and Information Systems, volume 2, no 2, Oktober 2018

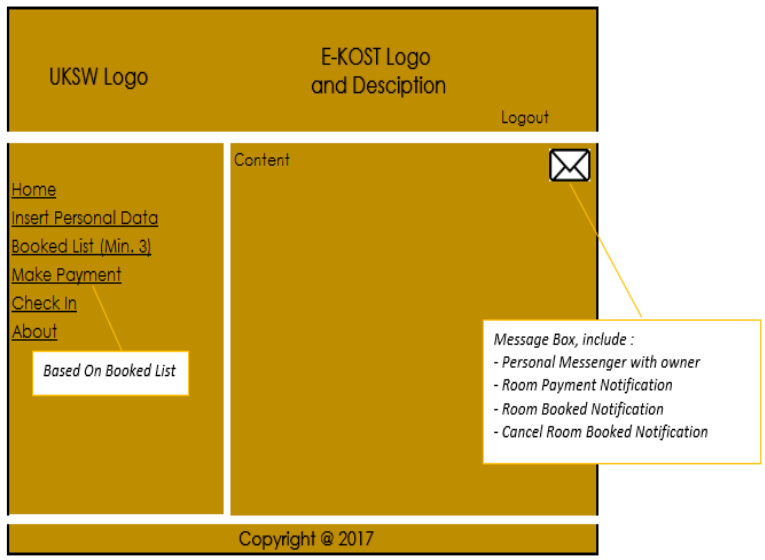

Gambar 6. Desain Interface Halaman Utama Mahasiswa (User Individu)

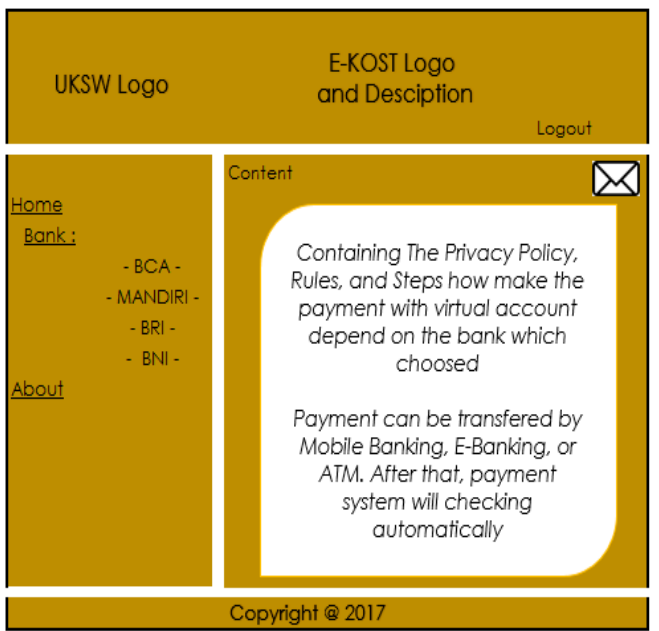

Gambar 7. Desain Interface Halaman Make Payment By Mahasiswa
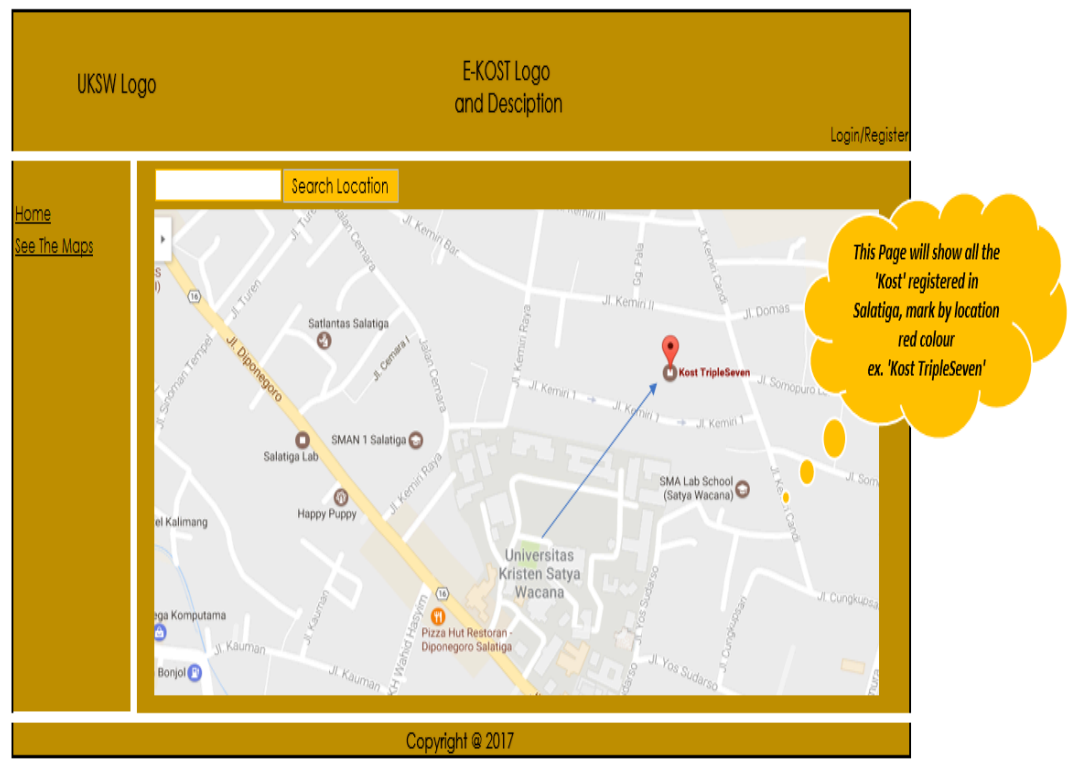

Gambar 8. Desain Interface Search By Google Maps 


\section{PEMBAHASAN}

\subsection{Desain Interface Umum Aplikasi}

Pada bagian ini, desain interface yang dibangun dibuat seperti struktur umum sebuah halaman web, yang mencakup header, badan content, serta footer. Header mencakup tampilan logo UKSW, karena dikhususkan untuk mahasiswa UKSW, kemudian ditambah dengan logo aplikasi sendiri yang berisi nama juga deskripsi aplikasi. Pada bagian content terdapat 2 bagian, yaitu display menu dan display content. Display menu bertujuan untuk menampilkan menu apa saja yang disediakan oleh aplikasi yang bertujuan untuk membantu users. Pada bagian display content, berisi tampilan dari menu yang dipilih.

\subsection{Desain Interface Layout Utama}

Pada bagian ini, terdapat 4 (empat) menu utama yang terletak di bagian kiri atau bagian display menu, yaitu home, search by categories, search by google maps, dan about. Setiap menu memiliki fungsi atau kegunaan masing - masing sesuai dengan kebutuhan si pengguna. Menu home sebagai home base pada aplikasi ini berfungsi untuk mengembalikan aplikasi ke dalam tampilan awal, oleh karena itu, disetiap menu akan disisipkan menu home sebagai default. Menu search by categories berfungsi untuk mencari kost berdasarkan kriteria yang disediakan, sehingga pengguna bisa dengan bebas mencari kost sesuai kebutuhan masingmasing. Menu search by google maps berfungsi mencari kost dengan langsung melihat peta digital yang telah disediakan oleh google, namun dengan syarat, smartphone harus selalu terhubung dengan koneksi internet. Menu terakhir adalah about, menu ini hanya akan menampilkan info mengenai aplikasi. Menu ini sama seperti menu home, dimana akan dijadikan menu default, sehingga akan selalu disisipkan pada setiap menu.

\subsection{Desain Interface Search by Categories}

Pada bagian ini, terdapat 4 (empat) menu utama dan 11 (sebelas) sub menu, diantaranya adalah menu home, menu facilities yang terdiri atas 7 (tujuh) sub menu, antara lain swimming pool, parking area, wifi hostspot, kitchen, security service, bathroom inside, dan tv, menu price yang terdiri atas 4 (empat) sub menu, antara lain $<300.000,>300.000,<1.000 .000$, dan $>1.000 .000$, dan yang terakhir menu default about. Pada bagian inilah mahasiswa dapat mencari kost sesuai dengan fasilitas yang dibutuhkan dan tak lupa dengan penyesuaian budget yan dimiliki. Apabila mahasiswa telah memilih salah satu fasilitas dan range harga yang sesuai, badan content akan secara otomatis menampilkan kost mana saja yang memenuhi kriteria tersebut. Pilihan range harga yang dibuat diambil dari harga rata-rata kost yang telah disurvey terlebih dahulu.

\subsection{Desain Interface Search by Google Maps}

Pada bagian ini, mahasiswa akan lebih mudah lagi dalam memilih kost mana kah yang ingin dituju. Maksudnya adalah peta digital atau google maps akan menampilkan kost mana sajakah yang telah bergabung dengan aplikasi E-KOST ini. Hal itu ditandai dengan adanya tanda merah yang berbentuk lokasi pada setiap lokasi kost. Mahasiswa hanya tinggal mengetik nama kost yang dituju pada bagian search, dan aplikasi dengan otomatis menunjukkan akan menunjukkan kost yang dimaksud. Apabila kost yang dituju tidak terdaftar, maka google maps tidak akan menampilkan content apa-apa. Search by google maps ini juga berguna untuk melihat radius atau jarak tempuh dari kampus UKSW menuju ke kost yang diinginkan. 


\subsection{Desain Interface Halaman Utama Mahasiswa (User Individu)}

Pada bagian ini, mahasiswa yang sudah melakukan registrasi dan login akan mendapatkan 1 (satu) halaman personal. Halaman ini memiliki 6 (enam) menu utama, diantaranya adalah menu home, menu insert personal data yang berguna mengisi data diri, menu booked list (max. 3) yang berfungsi sebagai list kamar kost mana saja yang telah di booking dengan maksimal 3 kamar, menu make payment yang berguna untuk membayar tagihan bookingan kamar, menu check in yang berguna untuk melakukan check in pada saat telah menempati kost, dan yang terakhir adalah menu default about. Menu yang menjadi pembeda dari semua aplikasi pencari kost yang ada adalah adanya sistem make payment. Sistem ini berfungsi untuk membayar kamar yang telah di booking dengan pengecekan secara otomatis. Halaman ini juga di lengkapi dengan message box yang berguna untuk melakukan conversation dengan owner terkait kamar yang akan dipesan, notifikasi pembayaran kamar, notifikasi pemesanan kamar, dan notifikasi pembayaran.

\subsection{Desain Interface Halaman Utama Owner / Pengelola Kost (User Bisnis)}

Pada bagian ini, owner atau pengelola kost yang sudah melakukan registrasi dan login akan mendapatkan 1 (satu) halaman personal seperti halnya halaman untuk mahasiswa. Tetapi yang membedakan adalah menu yang terdapat pada halaman ini. Menu yang tersedia pada halaman ini adalah 6 (enam) menu utama dan 3 (tiga) sub menu, diantaranya adalah menu home, menu insert personal data yang berguna untuk mengisi data diri, menu insert data kost yang berguna untuk menginput data kost seperti gambar dan deskripsi, menu see member yang berguna untuk melihat siapa saja yang sudah melakukan pemesan kamar (booking), menu payment yang terdiri atas 3 (tiga) sub menu yaitu room payment, room booked, list of payment, dan menu default about. Disini, owner diberikan satu fasilitas khusus yang memungkinkan owner untuk melakukan block pada mahasiswa yang sudah melakukan booking. Hak akses ini diberikan karena mungkin kost tersebut memiliki kriteria tersendiri dalam menerima anak kost. Halaman ini juga dilengkapi dengan message box yang kegunaannya kurang lebih sama seperti yang dimiliki oleh message box di halaman mahasiswa.

\subsection{Desain Interface Halaman Make Payment by Mahasiswa}

Pada bagian ini, mahasiswa yang telah melakukan booking atau pemesanan kamar, diwajibkan melakukan pembayaran, dimana bertujuan sebagai tanda jadi bahwa kamar tersebut akan di tempati. Halaman ini memiliki 3 (tiga) menu utama dan 4 (empat) sub menu, diantaranya pilihan bank seperti BCA, Mandiri, BNI, dan BRI, keempat bank tersebut dipilih karena merupakan bank yang paling umum digunakan. Pembayaran dapat dilakukan dengan menggunakan 3 (tiga) cara, yaitu ATM transfer, mobile banking, dan internet banking. Sistem ini menyediakan virtual account sehingga dana yang masuk akan langsung di cek secara otomatis dalam waktu kurang lebih 10 menit.

\section{KESIMPULAN}

Kesimpulan yang dapat diambil dari penyusunan penelitian yang telah dilakukan pada rancang bangun aplikasi mobile E-KOST ini adalah:

1. Aplikasi pencarian E-KOST ini dapat mempermudah mahasiswa dalam menemukan informasi serta lokasi kost yang sesuai dengan kebutuhannya. Aplikasi ini juga sangat membantu pengelola kost dalam mempromosikan kost yang dimiliki.

2. Aplikasi E-KOST ini dilengkapi dengan teknologi located based service (LBS) yang memudahkan mahasiswa untuk melihat radius jarak kost dan kampus UKSW melalui peta digital atau google maps. 
3. Aplikasi E-KOST dengan basis android ini sangat user-friendly, menggunakan bahasa yang tidak terlalu rumit, dan fleksibel, sehingga orang awam sekalipun dapat menggunakannya.

\section{SARAN}

Penulis berharap kedepannya rancang bangun aplikasi E-KOST ini bisa di kembangkan ke dalam tahap dan metode selanjutnya. Tahap tersebut dapat meliputi pengembangan metode penelitian dan perancangan aplikasi. Sehingga prototype yang telah dibuat dapat segera dirancang serta diimplementasikan pada smartphone dengan basis android.

\section{DAFTAR PUSTAKA}

[1] Safaat H, Nazruddin. 2015. Rancang Bangun Aplikasi Multiplatform (Android, IOS, Windows Phone, Blackberry, Symbian). Penerbit: Informatika.

[2] Kosasi, S. 2014. Sistem Informasi Geografis Pemetaan Tempat Kost Berbasis Web. Pontianak : STMIK Pontianak.

[3] Setiyawan, H. 2013. Sistem Informasi Tempat Kost Di Sekitar Universitas Muhammadiyah Surakarta. Surakarta: Universitas Muhammadiyah Surakarta.

[4] Haryanto, E.M.O.N. 2013. Perancangan Aplikasi Mobile Pencarian Lokasi Penyewaan Rumah Kost Berbasis Android di Kota Yogyakarta. AMIKOM Yogyakarta

[5] Sholiq. 2006. Pemodelan Sistem Informasi Berorientasi Objek dengan UML. Penerbit : Graha Ilmu

[6] http://www.mandalamaya.com/pengertian-gps-cara-kerja-gps-dan-fungsi-gps/. Diakses tanggal 1 Februari 2017.

[7] http://romisatriawahono.net/2006/04/29/menyegarkan-kembali-pemahaman-tentangrequirement-engineering/. Diakses tanggal 1 Februari 2017. 